\title{
Methoxy-functionalized mesostructured stable carbon catalysts for effective biodiesel production from non-edible feedstock
}

\begin{abstract}
The nano-architectured $\mathrm{Ca}(\mathrm{OCH} 3) 2 / \mathrm{AC}$ catalyst was prepared through hydrothermal process. In this work, the controlled structural growth and morphology of nano-architectured $\mathrm{Ca}(\mathrm{OCH} 3) 2 / \mathrm{AC}$ catalyst were reported and their conversion activity from non-edible oil source (crude jatropha oil) to biodiesel production was also evaluated in this study. Remarkable difference in catalytic activity for biodiesel production among these samples was observed. It shows that the catalytic properties of the hydrothermal synthesized catalyst was improved by exposing the catalytic active $\mathrm{OCH} 3$ predominantly on the surface of catalyst. The 0.4-OMe/AC catalyst with methanol/oil molar ratio of $12: 1$, agitation speed of $600 \mathrm{rpm}$ and $3 \mathrm{wt} \%$ of catalyst provided maximum biodiesel yield of $98.65 \%$ at $60{ }^{\circ} \mathrm{C}$ for $1 \mathrm{~h}$ reaction time. The catalyst exhibited outstanding stability where negligible $\mathrm{Ca} 2+$ leaching was detected and the recovered catalyst was reused in 8 successive cycles without significant loss in activity. Therefore, this kind of bimodal porosity catalyst is said to exhibit very high activity, stability, and recyclability, which entailed potential saving and affordable biodiesel production possibilities.
\end{abstract}

Keyword: Biodiesel; Nano activated charcoal; Anadara granosa; Meso-microporous; Transesterification 